\title{
Analysis on the Feasibility of Introducing the National Instrument Bamboo Flute into the Music Class of Primary and Secondary Schools
}

\author{
Ningbo Zhou ${ }^{1, *}$ \\ ${ }^{1}$ Mianyang Normal University, Mianyang, Sichuan 621000, China \\ "Corresponding author. Email: 1046290187@qq.com
}

\begin{abstract}
The introduction of bamboo flute into classroom as an instrument has changed the form of the traditional music classroom and diversified the music classroom. In this way, the learning enthusiasm of students has been greatly improved, and their music quality has also been improved along with it. This has a great effect on the development of music education in primary and secondary schools and the promotion of national music. This article carries out the feasibility analysis of the introduction of bamboo flute into the elementary and secondary school music classroom from the aspects of the advantage of its introduction, existing problems, improvement ideas and the impact on students' social life.
\end{abstract}

Keywords: Classroom teaching, National instrumental music, Interest, Music quality.

\section{INTRODUCTION}

With the continuous progress of the times and the continuous reform of education, the state education department established the educational concept of " fostering virtue through education" in 2013, and proposed that more attention should be paid to the cultivation and education of art for primary and secondary school students. James Moser, the famous American psychologist of music education, once pointed out incisively, "Instrumental music teaching can be said to be a bridge leading to better experience of music; in fact, it itself is a wide range of music learning field, where it provides music teaching with the possibility of unique and happy music education value and effect. The children are full of joy when learning, and under the guidance of their teachers, they will be able to gradually make this possibility their own." [6] The introduction of instrumental music teaching into the music classroom of primary and middle schools is a further measure on the basis of ordinary music education, and also an important way to improve the music quality of primary and middle school students. Bamboo flute is known as China's oldest national wind instrument. Bamboo flute has the characteristics of ethnic representativeness, popularity, convenience to carry and moderate price. Therefore, it can be inferred that bamboo flute is suitable for popularization and promotion in music classes of primary and secondary schools. Therefore, introducing the bamboo flute into the classroom for musical instrument teaching, has changed the traditional form of music classroom and made music classroom more diversified, which also improved students enthusiasm for learning greatly and helped to improve their music quality. This is of great significance in developing music education in primary and secondary schools and promoting national music.

\section{ADVANTAGES OF THE INTRODUCTION OF BAMBOO FLUTE INTO THE ELEMENTARY AND SECONDARY SCHOOL MUSIC CLASSROOM}

Bamboo flute is a national musical instrument with a long history and a wide spread in China. It itself is a musical instrument with simple structure, small volume and light weight and it is easy to carry. The price is also very moderate, in 300 yuan to 500 yuan or so one can buy a better bamboo flute. 
Compared with other musical instruments, bamboo flute has the characteristics of low cost and affordable price, which exactly meet the conditions of collective learning for primary and secondary school students. The bamboo flute is a true "green instrument." It can be called a folk handicraft, all made of pure natural materials of bamboo. Through the hands of professional flute makers, a very exquisite musical instrument - bamboo flute can be presented in people's sight. Nowadays, many economically developed countries are advocating "green things" from nature. In such a context, the bamboo flute fully shows its own unique charm. It not only has a high national art value, but also has a very important environmental education significance, and is deeply loved by people around the world. Bamboo flute can produce diverse timbres. By playing different timbre, the player can show the different style of music. It can be beautiful, peaceful and poetic, such as "The Song of Herdsmen" written by Jan Guangyi. It can also be loud and bright, such as Wei Xianzhong's "Busy in Delivering Grain Hastily".

\subsection{It Is Conducive to Improving Students' Ability of Solfeggio and Spectrum Recognition}

The most basic ability for instrument learning is the identification of spectrogram, which is also true of learning bamboo flute. The learning of bamboo flute requires students to use their mouth, hands, eyes and ears to blow, play and listen coordinately. After a long period of study and accumulation, students not only learn to play the bamboo flute, but also improve their ability to read music. Students can feel the beauty of rhythm, melody and harmony in the music by blowing, which not only promotes the teaching of solfeggio, but also enables students to accept the influence of national art invisibility. Mr. Hugo once said, "There are three keys to the treasure house of human wisdom: numbers, literature, and musical notes." Playing bamboo flute requires not only memorizing music, but also mastering the rhythm, speed and strength of the music, which requires the coordination and cooperation of various body organs such as mouth, hands, eyes and ears. These kinds of multi-direction thinking makes students' left and right brains exercise and develop in a balanced way. Moreover, flute playing can make students relax and adjust in their tense study and life so as to improve their learning efficiency.

\subsection{It Contributes to Improving Students' Singing Skills and Knowledge}

Bamboo flute is a blowing instrument, which is very helpful for training students' breath, especially the practice of "prolonged sound". Imperceptibly, it is very helpful for students' breathing sinking and breath control when they are singing. Every musical instrument has its own fixed pitch, and so does the bamboo flute. In the process of playing, students naturally develop a sense of intonation, which also solves the problem of intonation when students sing. At the same time, learning bamboo flute can also "foster strengths and circumvent weaknesses". Some students are not confident because of the lack of natural voice conditions, and they are willing to sing but not able to do so. They can learn musical instruments so as not to be rejected by the door of music.

Learning the bamboo flute is not only about playing and singing, but also about learning the background of the music. Bamboo flute is a national wind instrument in China. Long-term learning of bamboo flute allows the learner to come into contact with different ethnic music in different regions, which involves local customs, natural knowledge, politics, economy, history, geography and so on. Therefore, by learning bamboo flute, students can expand their horizons, increase their knowledge and understand national culture.

\subsection{It Is Helpful to Improve Students' Self- confidence}

Quality-oriented education is for every student, and there will be differences between students. The same problem can be encountered by students when they learn the bamboo flute. Students with a strong sense of music tend to learn faster than those with a weak sense of music, which also leads to the latter in learning easy to show inferiority, weariness, quit and other emotions. In view of this phenomenon, the group teaching method can be adopted. In a group of four to five students, the one with a relatively better sense of music can be appointed as the little teacher. In the group, students can learn from each other, supervise each other, help each other, and finally achieve common progress. In this way, students can benefit from and enjoy the music to one's heart's content and make friends. In this way, not only can students with weaker sense of music get help and exercise in group learning, but the learning progress of students throughout the class also get a good balance. The entry of bamboo 
flute into music classroom has changed the traditional music classroom teaching, but also enriched the teaching content. For the students with poor sound condition or in the voice change period, this improves their self-confidence and the enthusiasm of learning music courses. At the same time, the bamboo flute also has the characteristics of diversity. After learning the bamboo flute, students will have a certain foundation in learning other musical instruments, like cucurbit flute, desolate, Bau, ocarina and clarinet, etc. Since these wind instruments and bamboo flute have similar learning methods, so it is relatively easy for students to learn them. Therefore, doing a good job of the necessary groundwork and going step by step will play a great help to the self-confidence of students.

\subsection{It Is Beneficial to Improve the Quality of Music Class}

Bamboo flute has a wide range of tones, suitable for playing various kinds of music, and its pronunciation and fingering are relatively simple. Compared with traditional Chinese musical instruments such as zither, erhu, dulcimer and pipa and some western musical instruments, bamboo flute does not require so much money and skill. Therefore, bamboo flute is acceptable for primary and middle school students. Based on students' psychological acceptance of this musical instrument, through the teacher's professional teaching, students will have a happy journey on the bamboo flute learning. In just one or two years, students can finally master an instrument successfully and play some relatively simple songs. At the same time, the teacher also improved the quality of the music class, in which students can not only sing the songs, but also can to blow out them with instruments in the music class.

\section{THE EXISTING PROBLEMS OF BAMBOO FLUTE IN MUSIC CLASS OF PRIMARY AND MIDDLE SCHOOLS AND IMPROVEMENT IDEAS}

The introduction of bamboo flute into the classroom of primary and middle school is for the diversification of music class. The new concepts will incur a series of problems, which can only be implemented smoothly after being improved.

\subsection{Communication Between Schools and Parents}

To introduce flute into the music class of primary and middle school, the first thing to do is to ensure the smooth communication between school leaders and parents. The recognition and support of school leaders and parents is critical for whether the special music programmer of music teachers "introducing flute into the music class of primary and middle school" be held successfully or not. If it is approved by the school, then efforts should be made to persuade parents to buy their children the flute they need.

\subsection{Problems Worth Attention in the Selection of Flute for Students of Different Age Group}

In the process of instrument learning, students must have an instrument in accord with their own condition, which is also true of learning flute. It's necessary for the teacher to help students in their purchasing of a flute according to their age group. Especially for young learners, due to their young age and their still-growing body, flutes below D is not recommendable, as flutes below D have larger spacing between flute holes, not suitable for the little hands of primary students. In addition, since bamboo flutes in the tone below $\mathrm{D}$ require large lung capacity, it is a certain challenge for the immature primary school students. Therefore, when choosing bamboo flute for primary school students, teachers should pay more attention to these practical problems. It is generally recommended that the wooden flute in F or G tone is more easy for students to learn, and the teacher's teaching can be carried out smoothly.

\subsection{Fostering Students' Interest in a Progressive Way}

Due to the relatively young age of primary and middle school students, they will have a strong curiosity in the face of new things. At the beginning of learning, the students appear flighty and impetuous, eager for quick success. In order to avoid this kind of phenomenon appeared in the classroom teaching, teachers should cultivate students' interest, carry on the bamboo flute enlightenment teaching step by step, guide the students to go deep the musical instrument, and let them realize that to play pleasant music is not a matter of one or two days, but requires patient learning and accumulation for a long period. At the 
same time, teachers should adopt different teaching methods according to different ages of students, because students of different ages have different levels of learning acceptance. Therefore, teachers need to teach students in accordance with their aptitude, and adopt novel and rich teaching methods to focus students' attention and stimulate students' interest in teaching, so as to improve the teaching quality and students' learning effect. For example, multimedia teaching can be used in the teaching process, and students should be led to appreciate some concerts or watch concert video materials according to the actual situation.

\subsection{Developing the Inner Potential of Primary and Middle School Students}

In class, teachers cannot just teach students for the sake of instrument teaching, only blindly teaching musical skills. Instead, they should pay more attention to their teaching methods. When students encounter problems in the learning process, what teachers are supposed to do is to give students guidance and ways to learn knowledge, so as to let students try to solve problems by doing it themselves or by thinking about it step by step. At last, while affirming students, the teachers can correct their some problems at the same time. Only in this way can students really gain the fun and confidence in learning, and can the excellent national culture and art of China be inherited and developed.

\subsection{Taking Practice as the Focus of Teaching, and Theoretical Knowledge as the Auxiliary}

In the primary stage of bamboo flute learning, influenced by Chinese traditional exam-oriented education, teachers usually pay attention only to students' practice and ignore their mastery of music theory knowledge in order to ensure that students can get good results in exams. Subsequently, students can play a lot of music with much practice. But they can play the music only by cramming, and do not know about the beats and structure. As a result, many students cannot independently play some music works correctly without the guidance of teachers, which will play a certain hindering role in future classroom teaching of bamboo flute. Therefore, when training students' music skills, teachers should also make sure they master their music theory knowledge, so as to effectively improve their learning ability, more effectively explore and develop the potential of primary and middle school students, so that students can independently and accurately perform music works in the future learning process.

Bamboo flute is a traditional national musical instrument in China. The introduction of bamboo flute into the music class of primary and secondary schools enables the new generation of students to have a better understanding of the traditional national musical instrument and national culture of China, improve their national cultural conservation, and then inherit and develop the traditional national culture of China. And it is also conducive to the strict implementation of the aesthetic education policy, so as to improve the comprehensive quality of primary and middle school students.

\section{THE APPLICATION OF BAMBOO FLUTE IN TEACHING CLASSROOM}

In view of the bamboo flute entering the music class of primary and middle schools, music teachers should establish the correct teaching concept, so as to successfully introduce the bamboo flute into the music class of primary and middle schools.

\subsection{The Teaching of Basic Skills of Bamboo Flute Should Be the Primary Concern in the Music Class}

The focus of introducing bamboo flute teaching into the music class is not to train special talents, but mainly to train and improve the music literacy of primary and middle school students. Therefore, in the teaching process, teachers should first pay attention to whether students can achieve the correct performance posture, breathing methods and basic fingering. They should put their focus on the mastering of basic skills in students' practice, instead of teaching knowledge that is too challenging, lest the student will be weary of learning and quit. Only after students find their confidence and interest in learning bamboo flute, can the ultimate goal and effects of introducing the bamboo flute into the music class of primary and middle schools be finally achieved.

\subsection{The Teaching Modes Should Be Diversified}

The classroom teaching mode of bamboo flute should not be single. In addition to the new knowledge teaching, there should also be comprehensive class and review test class, etc. For 
example, in the comprehensive class, the bamboo flute skill teaching is counted as one part, and the other part can be integrated into the singing teaching in the classroom. The combination of blowing and singing makes the form of the classroom less simple. In the review class, the form of small solo or group performance and other forms of debriefing performance can be adopted. By enriching the classroom through different teaching forms, the class quality, the efficiency of students' mastery of knowledge and so on will be significantly improved.

\subsection{The Teaching Content Should Be Rich and Various}

In the bamboo flute teaching, the content should not only be monotonous and rigid knowledge, but there should be more and more rich elements, so as to improve the primary and secondary school students' interest in learning the bamboo flute. Therefore, the teaching of bamboo flute should not only focus on the practice of skills, but should start from multiple aspects, such as music, history and culture related to bamboo flute, and all aspects of knowledge that can provide help to students should be involved. Ensemble, chorus, and combination of playing and singing can also be used to cultivate the students' mutual cooperation consciousness and collective concept. Moreover, since the content of bamboo flute teaching is realized through the performance of music, in the bamboo flute classroom teaching, the selection of repertoire also has some limitations. Beautiful, short, catchy music, such as some traditional music, pop music or Chinese and foreign famous music is generally required.

\section{THE INFLUENCE OF BAMBOO FLUTE LEARNING ON SOCIAL LIFE OF PRIMARY AND MIDDLE SCHOOL STUDENTS}

The bamboo flute is introduced into the music class of primary and middle schools in order to improve the music quality of primary and middle school students and to develop and inherit Chinese national culture.

\subsection{Bamboo Flute Teaching Improves the Aesthetic Experience of Primary and Secondary School Students}

The final purpose of primary and middle school students of learning bamboo flute is to use bamboo flute to play beautiful music. Therefore, the basic aspect of learning bamboo flute is to feel and experience the beauty of its music. Bamboo flute itself is characterized by clear and bright timbre, and music of common styles can all be played by it. Therefore, teaching bamboo flute is not just about making students master the skills of bamboo flute, but also about deepening their understanding of music culture and cultivating their aesthetic ability from various aspects. This is the original intention of introducing bamboo flute into music classroom teaching in primary and secondary schools.

\subsection{Influence of Bamboo Flute on Study and Life of Primary and Middle School Students}

For primary and middle school students, patience is the biggest challenge for children. Since patience is something very abstract, and the process of cultivating patience is also abstract and long. In traditional music class, students tend to think the only activity is a music class is to sing songs, and they are getting out of patients with such music class. Therefore, in introduction of bamboo flute into the music class arouses students' new expectation of the music class. Musical instrument is an omnipotent learning tool, which not only lets one learn knowledge and skills, but also hone their will, exercise their perseverance and cultivate their patience and so on. Therefore, in the process of learning bamboo flute, primary and middle school students not only expand their musical knowledge, but also improve their will, perseverance and patience, etc.

\subsection{The Inheritance and Development of National Culture}

With the progress of the times, today's society has basically realized informatization. At present, China's music education basically follows the western education system. In primary and secondary schools in China, traditional national music is ignored and rejected by many students, who think that national music is vulgar and is not good enough in taste. The introduction of bamboo flute into the music class of primary and middle schools can not only change the traditional teaching mode of music class but more importantly, through learning bamboo flute, a Chinese national musical instrument, the students in primary and middle schools can understand more of the national music culture of China. In this way, China's own national instrumental music can get due attention in primary 
and secondary schools, so as to achieve the purpose of revitalizing national instrumental music and inheriting national culture.

\section{CONCLUSION}

To sum up, the introduction of national instrumental music into the music classroom of primary and secondary schools is a crucial link, which is the most effective way to carry forward the culture of national music, and also the most effective means to promote the development of national music. The teaching of national music is also a kind of patriotic education. The introduction of bamboo flute into the music class of primary and secondary schools is a relatively easy scheme among many Chinese national instruments. It is expected that through the program of "introducing bamboo flute into the music class of primary and secondary schools", students can understand China's traditional national culture, love China's national music, finally realize quality-oriented education, and promote the development of Chinese national music.

\section{AUTHORS' CONTRIBUTIONS}

This paper is independently completed by Ningbo Zhou.

\section{REFERENCES}

[1] Sang Qingsong. Educational Psychology [M]. Beijing: Beijing Normal University Publishing Group, 2008, 11. (in Chinese)

[2] Ruan Chengwu. Pedagogics [M]. Beijing: Beijing Normal University Publishing Group, 2008, 11. (in Chinese)

[3] Interpretation of Music Curriculum Standards in Full-time Compulsory Education. Beijing: Beijing Normal University Publishing Group, 2002, 5. (in Chinese)

[4] Xu Guoping. Tutorial of Flute for Children and Teenagers $[\mathrm{M}]$. Shanghai: Shanghai Music Press, 2008, 5. (in Chinese)

[5] Sun Ting. Inheritance and Innovation of Ethnic Music Teaching in Primary Schools [J]. Children's Music, 2003, (07). (in Chinese)

[6] Zhang Huiyuan. Discussion on the Teaching of Music Feeling. Family Education World, 2013, 10, P100. (in Chinese) 